\title{
Clinico-pathological features of tuberculosis due to Mycobacterium tuberculosis Uganda genotype in patients with tuberculous lymphadenitis: a cross sectional study
}

\author{
Dan Wamala ${ }^{1,3^{*}}$, Benon Asiimwe ${ }^{2}$,Edgar Kigozi ${ }^{2}$, Gerald Mboowa ${ }^{2}$, Moses Joloba ${ }^{2}$ and Gunilla Kallenius ${ }^{3}$
}

\begin{abstract}
Background: Tuberculous lymphadenitis is next to pulmonary tuberculosis as the most common cause of tuberculosis. Uganda genotype, one of the sub-lineages of Mycobacterium tuberculosis, is the most prevalent cause of pulmonary tuberculosis in Uganda. We here investigate the clinicopathological characteristics of patients with tuberculous lymphadenitis infected with $M$. tuberculosis Uganda genotype compared with those infected with $M$. tuberculosis non-Uganda genotype strains.

Methods: Between 2010 and 2012, we enrolled 121 patients (mean age 28.5 yrs, male 48\%; female 52\%) with tuberculous lymphadenitis, and categorized them by their M. tuberculosis genotypes. The clinical features and lymph node cytopathological parameters were compared between patients in the Uganda and non-Uganda categories using a crude and multivariable logistic regression model with adjustment for confounding factors.

Results: Of the 121 participants, 56 (46\%) were infected with strains of Uganda genotype. Patients infected with this genotype had significantly lower frequency of abdominal lymphadenopathy (odds ratio $0.4, p=0.046$ ) after adjusting for sex, age and HIV. Abdominal lymphadenopathy was also significantly associated with abnormal chest X-ray $(p=0.027)$.

Conclusion: Tuberculous lymphadenitis patients infected with M. tuberculosis Uganda genotype were significantly less prone to have abdominal lymphadenopathy indicating potential reduced ability to disseminate and supporting the concept that differences in M. tuberculosis genotype may have clinical implications.
\end{abstract}

Keywords: Tuberculosis, Extra pulmonary, Mycobacterium, Genotype, Abdominal lymphadenopathy, Uganda

\section{Background}

Tuberculosis (TB) remains a major global health problem. The latest estimates by WHO reveal that there were almost 8.6 million new cases in 2012 and 1.3 million TB deaths, 980000 among HIV negative people and 320 000 HIV-associated TB deaths [1]. Uganda is ranked $16^{\text {th }}$ among the 22 high burden countries with prevalence of 175 cases per 100,000 in 2012 of all forms of TB [2], and $60 \%$ of the patients are co-infected with

\footnotetext{
* Correspondence: dwamala@gmail.com

'Department of Pathology, Mulago Hospital and Makerere University College of Health Sciences, PO Box 7072, Kampala, Uganda

${ }^{3}$ Department of Clinical Sciences and Education, Sodersjukhuset,

Karolinska Institute, SE-171 77 Stockholm, Sweden

Full list of author information is available at the end of the article
}

HIV. The HIV prevalence in the Ugandan adult population is $6.7 \%$ [3].

Various host determinants such as sex, age and HIV coinfection influence the development of TB $[4,5]$, and the clinical outcome of Mycobacterium tuberculosis infection has been mainly attributed to host factors [6-9]. However, there is a broad variation in clinical pathological manifestations of TB in both HIV positive and HIV negative patients, which cannot be explained exclusively by host or environmental factors. Autopsy observations in Mulago Hospital, Kampala, have revealed severe or disseminated TB in HIV negative cases (unpublished information).

M. tuberculosis has evolved into a number of widely distributed and genetically diverse lineages and sub-lineages [10] exhibiting variable disease phenotypic characteristics 
demonstrated in epidemiological studies and animal models $[11,12]$. This together with diversity of the host immunological response may explain the wide clinicalimmunopathological spectrum of disease in those patients who cannot control the infection [13].

M. tuberculosis Uganda genotype causes up to $70 \%$ of pulmonary TB in Kampala [14], and other districts of Uganda [15,16]. The Uganda genotype as cause of other disease manifestations has however not been studied. Although TB is mainly a pulmonary disease, $M$. tuberculosis can infect any part of the body. Extrapulmonary TB (EPTB) has been reported in 15-20\% of HIV-negative patients $[17,18]$, and the proportion is much higher in patients infected with HIV [17-19]. EPTB is thought to be caused by spread of bacteria by the haematogenous route from an initial focus in the lung and as such to represent a disseminated form of TB disease [20]. The commonest manifestation of EPTB is in most settings peripheral lymphadenitis $[19,21,22]$.

The aim of this study was to assess the clinicopathological features of TB in patients with peripheral TB lymphadenitis and to determine whether those infected with strains of Uganda genotype display specific clinical, radiological and cytopathological features compared to those infected with other genotypes of M. tuberculosis.

\section{Methods}

\section{Ethical considerations}

Ethical approval for the study was granted by the Institutional Review Board of Makerere University School of Medicine and the Uganda National Council for Science and Technology. Written informed consent to obtain samples as well as to use isolates from the samples for studies was obtained from all enrolled study participants or their legal guardians.

\section{Study population}

This was a cross sectional study conducted between February 2010 and July 2012, at the fine needle aspiration clinic, Mulago Teaching and National Referral Hospital, Kampala and Department of Medical Microbiology, Makerere University College of Health Sciences. Patients with persistent lymphadenopathy at this hospital are routinely referred from medical or surgical units. In this study, 283 ethnic African patients with superficial lymphadenopathy and evening fever were enrolled.

Patients presenting with superficial persistent lymph node enlargement, and cytological and clinical features of TB were recruited into the study after written informed consent. The clinical features of TB included unintentional weight loss, fatigue, night sweats, evening fevers for more than 4 weeks and loss of appetite. Tuberculous lymphadenitis was defined based on: i) superficial lymphadenopathy equal to or greater than $1 \times 1 \mathrm{~cm}$ persistent for more than 4 weeks. ii) cytological features consistent with $\mathrm{TB}$ and iii) culture of lymph node aspirate positive for M. tuberculosis complex bacteria with or without prior Ziehl Neelsen (ZN) or Auramine acid fast bacilli (AFB) positive smear. The patients were anti-tuberculous drug naive and had failed to respond to conventional antibiotics. Participants who consented to HIV testing were screened for antibodies against HIV 1 and HIV 2 by enzyme-linked immunosorbent assay (ELISA) after pre-test counseling. Patients were excluded if they had a neoplastic condition, culture negative lymph node aspirates or did not consent to fine needle aspiration (FNA).

After capturing the demographic data such as age, sex and HIV status, the participants' relevant clinical history suggestive of TB was recorded. They were examined and in particular assessed for clinical, radiological and pathological parameters including lymph node site, size and consistence.

Abdominal ultrasound scans were performed to look for abnormal findings suggestive of abdominal TB with a Medison SonoAce 9900 ultrasound machine (Seoul, Korea) using a $7.5 \mathrm{mHz}$ convex probe and a $7.5 \mathrm{mHz}$ linear probe. The presence of abdominal lymphadenopathy was considered significant if there were more than three lymph nodes or at least one lymph node $12 \mathrm{~mm}$ or more in size. Lymph nodes were sought in the paraaortic region, the porta hepatis region, the mesentery and the splenic hilum. The role of abdominal ultrasound in diagnosis of extrapulmonary or disseminated TB was previously evaluated, and a significant correlation was found between abdominal lymphadenopathy and active TB as diagnosed by smear or culture [23], thus abdominal ultrasound was found valuable in diagnosing EPTB [24].

Chest $x$-ray was performed with patients in standing posture and holding their breath, using a Schimadzu machine (Shimadzu-Japan), with the patient's chest positioned $150 \mathrm{~cm}$ away from the $\mathrm{x}$-ray tube. The chest X-ray was considered abnormal when it showed any of the following: lobar/segmental consolidation, cavitation, fibronodular lesions, pleural effusion, hilar and mediastinal lymph nodes, linear interstitial disease or miliary disease.

\section{Fine needle aspiration (FNA)}

FNA was performed on consenting participants fulfilling inclusion criteria. Under aseptic conditions, the lymph node was immobilized with left hand to entirely access it while the right hand was used to aspirate. Using a 23G cutting needle and a $2 \mathrm{ml}$ syringe lymph node aspiration was done with constant suction in a fan like fashion until the material appeared in the hub. The suction was then released, the needle withdrawn and the patient was asked to apply pressure to the punctured wound to prevent bleeding. Lymph 
node aspirates were cytologically analyzed and cultured for mycobacteria.

\section{Cytomorphology}

Aspirated lymph node material was expressed on to a glass slide with $3 \mathrm{ml}$ of syringe air. The material was gently spread on the second slide by pulling the two slides facing each other gently apart. For each aspirate four slides were prepared, one for Papanicolaou stain, two for acid fast bacilli (AFB) stain (Ziehl Neelsen and fluorochrome respectively) while one was air dried for Romanowski stain (Biostains, UK) using standard protocols $[25,26]$. Cytomorphological findings were recorded in terms of presence or absence of granuloma formation, necrosis, Langhans giant cells and epitheloid transformed macrophages [27].

\section{Identification of the Uganda genotype strains Sample processing for culture}

Five $\mathrm{ml}$ of lymph node aspirate in distilled water was homogenized by digestion and decontaminated using the standard N-acetyl-L-cysteine (NALC)-Sodium hydroxide/Sodium citrate method [28] and the resulting sediment used for making smears and cultures on solid Lowenstein Jensen medium and the BACTEC MGIT 960 (Becton Dickinson Diagnostic Systems, Sparks, Md). Positive cultures were subjected to AFB staining for confirmation of mycobacterial growth.

DNA was extracted from growth using standard protocols $[29,30]$ (Reagents from Sigma life Science, USA). Capilia TB assay (TAUN, Numazu, Japan), based on lateral flow immunochromatographic detection of a protein which is highly specific for MTB complex(MPB64) was used to differentiate $M$. tuberculosis complex isolates from non-tuberculous mycobacteria [31].

\section{Spoligotyping}

All $M$. tuberculosis complex strains were assayed by spoligotyping using standard protocols [32] (reagents from Ocimum Biosolution). Isolates were assigned specific spoligotype signatures (SIT) according to SITVITWEB database [33], which were used to determine their specific genotypes. The T2 lineage, to which the Uganda genotype belongs was identified. T2 lineage strains are characterized by a spoligotype pattern lacking spacers 40 , or both 40 and 43 as previously described [34].

\section{Region of difference (RD) analysis}

This PCR based M. tuberculosis complex typing method depends on chromosomal region of difference (RD) deletion loci. The patterns of amplification products are visualized by agarose gel electrophoresis. All isolates were analyzed for a deletion at the RD724 locus, which is specific for the Uganda genotype as previously described [14].
For statistical analyses, genotypes were grouped into two: Uganda genotype (T2 strains with a deletion at the RD724 locus) and non-Uganda genotype (all other strain types in the collection).

\section{Statistical analyses}

Clinical and socio-demographic data earlier collected were entered into Epidata v 3.1 and exported to SPSS v21.

Descriptive analysis was used for the baseline characteristics. Pearson chi square was used to measure differences between the two $M$. tuberculosis genotype categories with respect to demographic parameters. The independent $t$-test was used to compare the means of the continuous variables, age and lymph node size. Crude and multivariable logistic regression analysis was used to explore clinical, radiological and pathological features of the Uganda genotype compared with nonUganda genotypes of $M$. tuberculosis controlling for potential confounding factors including sex, age and HIV status. Odds ratios (ORs) with corresponding 95\% confidence intervals $(\mathrm{CI})$ were calculated and are presented. A P value of $<0.05$ was considered evidence of significant difference.

\section{Results}

Of the 283 patients with superficial lymphadenopathy and clinical features of TB and with cytological features consistent with tuberculous lymphadenitis enrolled, 121 (43\%) had lymph node aspirates that turned out culture positive for M. tuberculosis complex, of which 55 (45\%) were also $\mathrm{ZN}$ smear positive. 29 (53\%) of these were Uganda genotype. Three (1.8\%) samples were positive for non-tuberculous mycobacteria, while 159 (56\%) turned out culture negative and were all excluded from further analysis.

\section{Patient characteristics}

Of the 121 patients with tuberculous lymphadenitis 62 $(52 \%)$ were female and 58 (48\%) male, mean age being 28.5 years (range 2-61 years) (Table 1). The gender of one patient was not recorded. Of 114 patients who consented to HIV testing 75 (66\%) were HIV positive while 39 (34\%) were HIV negative. Seven patients did not consent to HIV testing. The major clinical signs were: a history of evening fever (all patients), night sweats $(\mathrm{n}=98$, $81 \%)$ and cough $(\mathrm{n}=57,47 \%)$. Sixty-six $(55 \%)$ patients presented with lymphadenitis at a single site, and of those 25 (38\%) had no signs of pulmonary and/or abdominal disease. Seventy-five (62\%) patients were found to have pulmonary and/or abdominal involvement in addition to superficial lymphadenopathy.

The lymph node site distribution among the patients were as follows: right posterior cervical triangle 21 $(17.4 \%)$, right anterior cervical triangle $10(8.3 \%)$, left 
Table 1 Baseline characteristics of patients infected with Uganda and non-Uganda strains

\begin{tabular}{lccc}
\hline & $\begin{array}{c}\text { Uganda genotype } \\
\mathbf{n}=\mathbf{5 6}(\mathbf{4 6 \% )}\end{array}$ & $\begin{array}{c}\text { Non-Uganda genotype } \\
\mathbf{n}=\mathbf{6 5}(\mathbf{5 4 \% )}\end{array}$ & P-Value \\
\hline HIV Status & $31(61 \%)$ & $44(70 \%)$ & 0.311 \\
HIV + & $20(39 \%)$ & $19(30 \%)$ & \\
HIV - & & & \\
Age & $27($ SD 10) & $30($ SD 11) & 0.225 \\
Mean & & & \\
Sex: & $30(55 \%)$ & $32(49 \%)$ & 0.562 \\
Female & $25(45 \%)$ & $33(51 \%)$ & \\
Male & & & \\
\hline
\end{tabular}

Chi-square and $t$-test.

posterior cervical triangle 28 (23.1\%), left anterior cervical triangle $3(2.5 \%)$, left supra clavicular $2(1.7 \%)$, right supra clavicular $1(0.8 \%)$, left axillary $1(0.8 \%)$, generalized superficial lymphadenopathy $16(13.2 \%)$ and bilateral cervical lymphadenopathy 39 (32.2\%).

The mean lymph node sizes calculated using the independent samples t- test model were $3.8 \mathrm{~cm}$ (standard deviation, $\mathrm{SD}$ 1.8) for patients infected with non-Uganda genotypes and $3.4 \mathrm{~cm}$ (SD 2.0) for patients infected with Uganda genotype $(\mathrm{p}=0.305)$.

\section{Cytomorphological features}

In practically all FNA samples $(\mathrm{n}=113)$ there was necrosis (amorphous, caseous or suppurative). Granuloma were found in 93 (77\%), Langhans giant cells in 53 (44\%) and macrophages in 111 (92\%) cases (Figure 1).

\section{Abdominal ultrasound}

Sixty patients had abdominal lymphadenopathy, ie more than three lymph nodes, or at least one lymph node of more than $12 \mathrm{~mm}$ in size. The involved anatomic sites included the para-aortic region, the porta hepatis region, the mesentery and the splenic hilum.

\section{Chest X-ray}

Forty-seven patients had an abnormal chest X-ray, with 6 having lobar/segmental consolidation, 2 cavitation, 4 fibronodular lesions, 7 pleural effusion, 12 hilar and mediastinal lymph nodes, 7 linear interstitial disease, and 9 miliary disease.

\section{M. tuberculosis complex genotypes}

Spoligotyping revealed 54 distinct spoligotype patterns, of which $33(61 \%)$ patterns were available in the SITVITWEB and 21 (39\%) patterns were not found in the data base. Spoligotypes representing the Euro American lineage (to which the Uganda genotype belongs) were predominant (62\%), followed by the Central Asian Strain
(CAS) lineage (18\%). There were three Beijing strains and no Mycobacterium bovis.

On characterization by spoligotyping and RD724 deletion analysis, the $121 \mathrm{M}$. tuberculosis complex isolates yielded 56 (46\%) isolates of the Uganda genotype while 65 (54\%) were non- Uganda genotypes.

\section{Association between patient characteristics and Uganda genotype}

There were no statistically significant differences between patients infected with Uganda genotype and patients infected with non-Uganda genotypes with respect to the baseline parameters age, sex and HIV status (Table 1).

To investigate if there were differences in clinicopathological characteristics of the tuberculous lymphadenitis patients infected with Uganda genotype versus those infected with other genotypes, we assessed the clinical, radiological and pathological features of patients in the two groups (Table 2). Since the disease outcome following infection with $M$. tuberculosis may be influenced by confounding factors like age, sex and HIV, multivariable logistic regression was used with $M$. tuberculosis genotype, age, sex and HIV status entered into the model to adjust for these confounding variables.

There were no statistically significant differences between the two groups (Uganda versus non-Uganda) with respect to cough, fever duration (more or less than 6 months), night sweats, lymph node size, and chest $\mathrm{X}$ ray findings (Table 3). However, patients infected with Uganda strains were significantly less prone to have abdominal lymphadenopathy compared to those infected with non-Uganda strains (OR $0.4,95 \% \mathrm{CI}$ 0.2-0.4, $\mathrm{p}=0.014)$, even after adjusting for HIV infection, age and sex $(\mathrm{OR}=0.5,95 \%$ CI $0.2-1.0, \mathrm{P}=0.046)$. Of the 16 patients with generalized lymphadenopathy $5(31 \%)$ were infected with Uganda genotype strains while 11 (69\%) were infected with non-Uganda genotypes.

\section{Association of abdominal lymph node enlargement with features indicative of TB severity or dissemination}

Abdominal lymph node enlargement was significantly associated with abnormal chest X-ray findings $(\mathrm{p}=0.027)$, There was no statistically significant association between abdominal lymph node enlargement and generalized lymphadenopathy, AFB smear positivity or absence of granulomas (Table 4).

\section{Discussion}

In this cross-sectional study of patients presenting with tuberculous lymphadenitis and clinical signs of TB we found a high prevalence of infection at other sites, with 9 patients with miliary pulmonary TB at the extreme end of the disease spectrum, while only $38 \%$ of the 


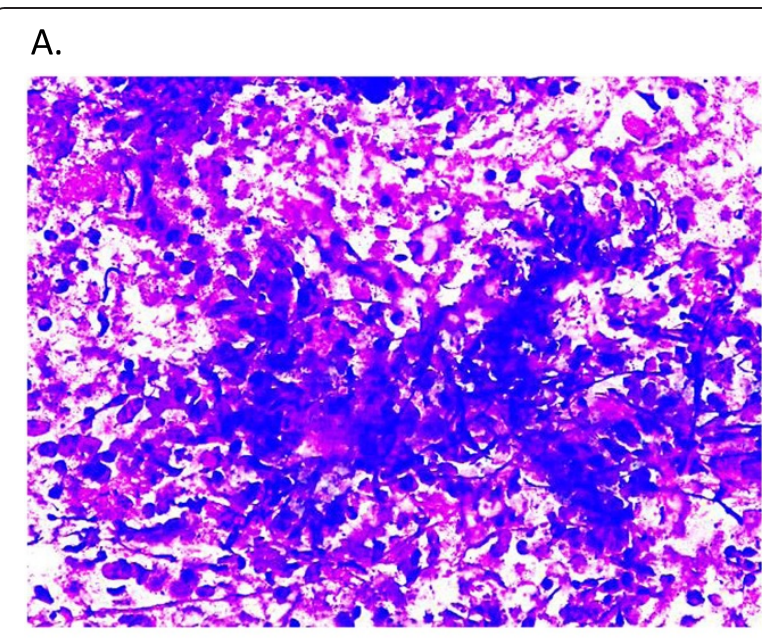

B.

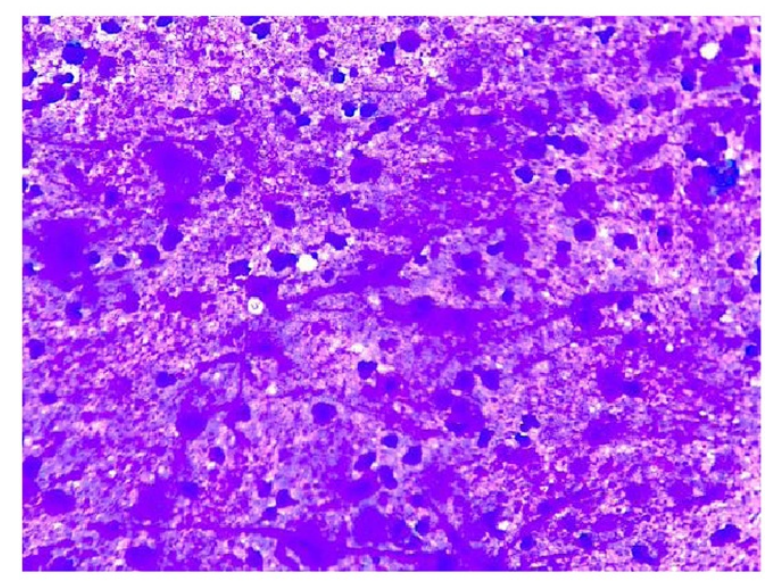

C.

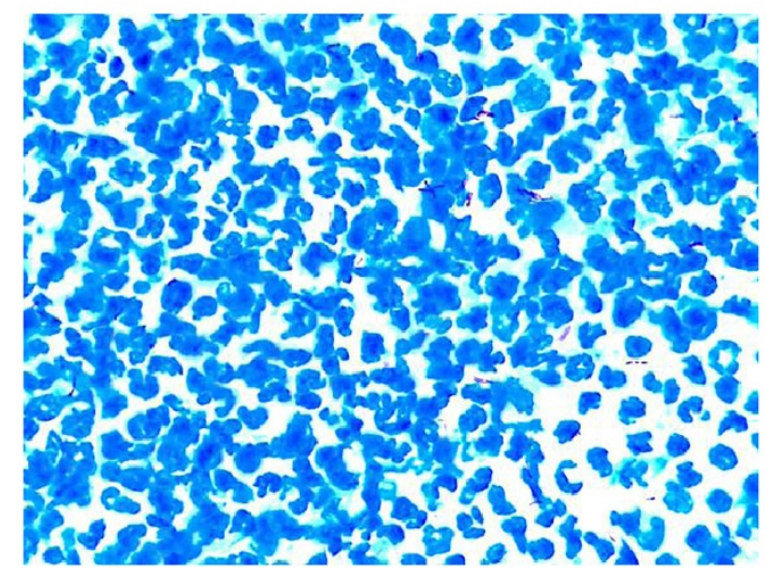

Figure 1 Cytomorphological features of tuberculous lymphadenitis. (A) Tuberculous lymphadenitis with chronic granulomatous inflammation comprising epitheloid cells, lymphocytes, multinucleated giant cells and caseous necrosis.

(B) Tuberculous lymphadenitis with amorphous necrosis containing a few lymphocytes. (C) Tuberculous lymphadenitis with suppurative necrosis and a number of AFBs. patients had single lymphadenitis with no abdominal or pulmonary engagement.

Lymphadenopathy (superficial as well as systemic, including abdominal lymphadenopathy) is regarded as a manifestation of EPTB, where the mode of infection includes haematogenous spread from a primary focus or in miliary TB, lymphatic spread from infected lymph nodes, ingestion of bacilli and direct spread from adjacent viscera [35]. There are indications that the homeostatic immune response in tuberculous lymphadenitis is fundamentally different from that of pulmonary TB [36].

Tuberculous lymphadenitis patients infected with Uganda genotype strains were significantly less prone to present with abdominal lymphadenopathy $(\mathrm{p}=0.014)$ than those patients infected with non-Uganda strains, even after adjusting for confounding factors including age, sex and HIV co-infection $(\mathrm{p}=0.046)$. Abdominal lymph node enlargement was itself significantly associated with abnormal chest $X$-ray findings $(p=0.027)$, one of the features indicative of TB severity or dissemination. Interestingly, the Uganda genotype which is responsible for close to $70 \%$ of pulmonary TB disease in our setting [14], in this study caused only $46 \%$ of the 121 cases of tuberculous lymphadenitis. Tuberculous lymphadenitis is the commonest form of extra pulmonary TB in high endemic areas [18,37]. Previous evidence also suggest that strains of the Euro-American lineage of M. tuberculosis to which $M$. tuberculosis Uganda genotype belongs less frequently cause EPTB [11,12].

Thus the Uganda genotype appears to have a reduced potential to disseminate and cause extra-pulmonary disease, and may inversely have a higher potential to cause pulmonary TB. Since pulmonary TB is more contagious than EPTB the Uganda genotype may have an advantage in transmission of TB which is reflected in the high incidence of this genotype in Uganda and surrounding areas [38]. The dominance of the Uganda genotype has however not been associated with pulmonary cavitation [39], which is associated with tissue liquafactive necrosis and cough generated aerosol, an efficient mechanism by which TB is spread.

A particular strain of Uganda genotype (SIT52) caused a large outbreak of TB in Sweden [40]. This strain exhibited extensive cell death of macrophages infected in vitro, with production of elevated amounts of tumor necrosis factor (TNF) compared to the virulent laboratory H37Rv strain [41]. The interplay of TNF and other cytokines in the early innate immune response is complex, but it is noteworthy that TNF neutralization in animal models including nonhuman primates resulted in disseminated disease in $M$. tuberculosis infected animals [42].

Risk factors for extra pulmonary TB include age, sex and HIV co-infection $[21,43,44]$. Not unexpectedly a high proportion (66\%) of the patients in this study were HIV-infected, a figure which is similar to studies of 
Table 2 Clinical and immunopathological parameters of patients infected with Uganda genotype and those infected by non-Uganda genotypes of $M$. tuberculosis

\begin{tabular}{|c|c|c|c|c|c|}
\hline \multirow[t]{2}{*}{ Patient characteristics } & \multirow{2}{*}{$\begin{array}{c}\text { Uganda/ } \\
\text { Non-Uganda n (\%) }\end{array}$} & \multicolumn{2}{|c|}{ Crude } & \multicolumn{2}{|c|}{ Adjusted* } \\
\hline & & OR $(95 \% \mathrm{Cl})$ & $P$-value & OR $(95 \% \mathrm{Cl})$ & $P$-value \\
\hline \multicolumn{6}{|l|}{ Clinical presentations } \\
\hline Fever less than 6 months & $39(70 \%) / 44$ (69\%) & $1.0(0.5-2.3)$ & 0.916 & $1.1(0.5-2.5)$ & 0.870 \\
\hline Night sweats & $43(77 \%) / 55(86 \%)$ & $0.5(0.2-1.4)$ & 0.200 & $0.5(0.2-1.4)$ & 0.213 \\
\hline Cough & $27(48 \%) / 30(46 \%)$ & $1.1(0.5-2.2)$ & 0.821 & $1.4(0.7-3.1)$ & 0.435 \\
\hline \multicolumn{6}{|l|}{ Radiological Presentations } \\
\hline Abnormal Chest X-ray & $20(43 \%) / 27(47 \%)$ & $0.8(0.4-1.8)$ & 0.624 & $0.8(0.4-1.9)$ & 0.644 \\
\hline Abdominal lymphadenopathy & $21(38 \%) / 39(60 \%)$ & $0.4(0.2-0.8)$ & 0.014 & $0.5(0.2-1.0)$ & 0.046 \\
\hline \multicolumn{6}{|l|}{ Lymph node Pathology } \\
\hline Single site lymphadenitis & $34(62 \%) / 32(50 \%)$ & $1.6(0.8-3.4)$ & 0.197 & $1.4(0.6-2.9)$ & 0.435 \\
\hline Generalized lymphadenopathy & $5(9 \%) / 11(17 \%)$ & $0.5(0.2-1.5)$ & 0.204 & $0.7(0.2-2.1)$ & 0.474 \\
\hline Lymph node $\geq 4 \mathrm{~cm}$ & $15(28 \%) / 28(45 \%)$ & $0.5(0.2-1.0)$ & 0.055 & $0.6(0.3-1.3)$ & 0.157 \\
\hline Necrosis & $52(93 \%) / 61(94 \%)$ & $0.9(0.2-3.6)$ & 0.827 & $0.8(0.2-3.4)$ & 0.741 \\
\hline Giant cells & $28(50 \%) / 25(38 \%)$ & $1.6(0.8-3.3)$ & 0.203 & $1.3(0.6-2.8)$ & 0.569 \\
\hline Macrophages & $53(95 \%) / 58(89 \%)$ & $2.1(0.5-8.7)$ & 0.290 & $1.5(0.4-6.9)$ & 0.577 \\
\hline Granulomas & 47 (84\%)/46 (71\%) & $2.2(0.9-5.3)$ & 0.091 & $1.9(0.8-4.8)$ & 0.196 \\
\hline Ziehl Neelsen positive smear & $29(52 \%) / 42(65 \%)$ & $0.6(0.3-1.2)$ & 0.152 & $0.7(0.3-1.5)$ & 0.348 \\
\hline
\end{tabular}

Adjusted $^{*}=$ Adjusted for Age, Sex and HIV status; $\mathrm{OR}=$ Odds ratio, $\mathrm{Cl}=$ Confidence Interval.

Logistic regression.

patients with extra-pulmonary TB in other high endemic African countries $[45,46]$. It is well known that HIV coinfection represents an increased risk of dissemination of TB involving multiple organs, through several immunological mechanisms not yet quite well understood [47], and infection with HIV increases the incidence and severity of abdominal TB [37]. Thus 7 patients with miliary $\mathrm{TB}$ were HIV-infected while the sero status of the remaining 2 patients was not known. However, HIVstatus did not affect the proportion of patients infected with Uganda genotype, and only marginally affected the negative correlation between Uganda genotype and abdominal

Table 3 Distribution of the chest abnormalities among the patients infected with Uganda genotype and non-Uganda genotypes

\begin{tabular}{llll}
\hline $\begin{array}{l}\text { Chest X-ray } \\
\text { abnormalities }\end{array}$ & Number & $\begin{array}{l}\text { Uganda } \\
\text { genotype }\end{array}$ & $\begin{array}{l}\text { Non-Uganda } \\
\text { genotypes }\end{array}$ \\
\hline Lobar/segmental consolidation & $6(12.8 \%)$ & $5(83 \%)$ & $1(17 \%)$ \\
Cavitation & $2(4.3 \%)$ & $0(0 \%)$ & $2(100 \%)$ \\
Fibro nodular lesions & $4(8.5 \%)$ & $2(50 \%)$ & $2(50 \%)$ \\
Pleural effusion & $7(14.9 \%)$ & $2(29 \%)$ & $5(71 \%)$ \\
Hilar and Mediastinal lymph & 12 & $5(42 \%)$ & $7(58 \%)$ \\
nodes & $(25.5 \%)$ & & \\
Linear interstitial disease & $7(14.9 \%)$ & $1(14 \%)$ & $6(86 \%)$ \\
Miliary disease* & $9 *(19.1 \%)$ & $5(56 \%)$ & $4(44 \%)$ \\
\hline
\end{tabular}

*7 patients are HIV positive, while the remaining 2 patients' sero-status was unknown. lymphadenitis, indicating that HIV-status was not important for the differences in clinical manifestations between Uganda and non-Uganda genotypes.

The indication of a lower tendency to form extrapulmonary disease by the Uganda genotype compared with

Table 4 Association of abdominal lymph node enlargement with features indicative of TB dissemination (i.e. generalized lymphadenopathy, abnormal chest X-Ray, Acid fast bacilli (AFB) positivity and absence of granuloma)

\begin{tabular}{ccc} 
Abdominal & No-abdominal & P-Value \\
lymphadenopathy & lymphadenopathy & \\
$\mathrm{n}=60(49.6 \%)$ & $\mathrm{n}=61(50.4 \%)$ & \\
\hline
\end{tabular}

Generalized lymphadenopathy:

$\begin{array}{llll}\text { Present } & 30(57 \%) & 23(43 \%) & 0.170 \\ \text { Absent } & 20(39 \%) & 19(30 \%) & \\ \text { Granuloma: } & & & \\ \text { Present } & 46(50 \%) & 47(50 \%) & 0.960 \\ \text { Absent } & 14(50 \%) & 14(50 \%) & \end{array}$

Abnormal findings on Chest X-ray:

$\begin{array}{llll}\text { Present } & 30(64 \%) & 17(36 \%) & 0.027 \\ \text { Absent } & 24(41 \%) & 34(59 \%) & \end{array}$

AFB smear positivity: (Ziehl Neelsen or fluorochrome stain)

\begin{tabular}{llll} 
Positive & $39(65 \%)$ & $29(47 \%)$ & 0.053 \\
Negative & $21(35 \%)$ & $32(53 \%)$ & \\
\hline
\end{tabular}

Chi-square test. 
the other genotypes is in line with a recent large study of TB cases that showed a relationship between phylogenetic lineage and clinical site (pulmonary versus extra pulmonary) of TB [48]. In a study from Vietnam disease caused by the Euro-American lineage was significantly more likely to be pulmonary than meningeal, which suggests that this lineage is less capable of extrapulmonary dissemination in this population [49].

Extrapulmonary disease has been associated with the East Asian/Beijing genotype [50]. Patients infected with strains of Beijing genotype were found to have significantly lower frequency of fever and pulmonary cavitation than those infected with other genotypes of $M$. tuberculosis [51], and were associated with characteristic radiological patterns [52]. These associations seem to hold for some populations and not for others [53,54], and may be explained by the fact that the Beijing lineage has evolved into distinct branches defined by specific RD deletions [55] with different impact on the immune response [56]. On the other hand there was no difference in lineage distribution between cases of pulmonary and extrapulmonary $\mathrm{TB}$ in a study from Ethiopia [57], a country with a high incidence of tuberculous cervical lymphadenitis [57], and a study from South Africa [58] found no significant relationship between mycobacterial genotype and EPTB. Yet, it is increasingly evident that the genetic diversity of $M$. tuberculosis strains contributes to the wide clinical spectrum of TB $[59,60]$.

The limitation of this study is the fact that unlike animal models, the patients live in a heterogeneous socio-economic environment which may confer varying susceptibility and resistance to TB. Factors like clinical stages of TB and/or HIV and immunosuppressive states like malnutrition and diabetes mellitus may contribute to disease outcome in TB patients.

\section{Conclusion}

In summary, tuberculous lymphadenitis patients infected with strains of Uganda genotype were significantly less prone to have abdominal lymphadenopathy and may be less susceptible to developing severe or disseminated TB. The frequency of Uganda genotype in this study was lower than the frequency of Uganda genotype reported for pulmonary TB in the same setting. Genotyping of $M$. tuberculosis may aid clinicians make better therapeutic decisions and predict patient prognosis.

Further studies are indicated to elucidate the clinicalpathological significance of the genetic diversity of M. tuberculosis strains and lineages in Uganda for understanding the outcome of infection with the Uganda genotype.

\section{Abbreviations}

TB: Tuberculosis; HIV: Human immunodeficiency virus; ZN: Ziehl-Neelsen; M. tb: Mycobacteria tuberculosis; MOTT: Mycobacteria other than tuberculosis;
MGIT: Mycobacteria other than tuberculosis; FNA: Fine needle aspiration; DQ: Diff. quick stain; Pap: Papanicolaou stain; OR: Odds ratio; Cl: Confidence interval.

\section{Competing interests}

The authors declare that they have no competing interests.

\section{Authors' contributions}

DW: Participated in the research conceptual development, drafting of manuscript, data acquisition, analysis and interpretation, and to intellectual content. EK: Participated in molecular biology studies and made substantial contribution to interpretation of data and intellectual discussion. GM: Participated in microbiology studies and contributed to intellectual content. GK: Participated in the conceptual development,drafting and critically revising the manuscript. Contributed substantially to the intellectual content and gave the final approval of the manuscript. BA: Participated in the research conceptual development, drafting and revising the manuscript and to the intellectual content. MJ: Participated in the research conceptual development and design and contributed to the intellectual content of the manuscript. All authors read and approved the final manuscript.

\section{Acknowledgements}

The Authors wish to thank Lina Benson for the assistance in data analysis. The study was supported by funds from the Swedish International Development Cooperation Agency through Makerere University-Karolinska Institute Research collaboration.

\section{Author details}

'Department of Pathology, Mulago Hospital and Makerere University College of Health Sciences, PO Box 7072, Kampala, Uganda. ²Department of Medical Micobiology, Makerere University College of Health Sciences, PO Box 7072, Kampala, Uganda. ${ }^{3}$ Department of Clinical Sciences and Education, Sodersjukhuset, Karolinska Institute, SE-171 77 Stockholm, Sweden.

Received: 21 August 2013 Accepted: 27 March 2014

Published: 2 April 2014

\section{References}

1. WHO: WorldHealthReport; 2013. http://www.who.int/tb/publications/ global_report/gtbr13_executive_summary.pdf.

2. WHO: Global Tuberculosis Control: Surveillance, Planning, Financing. Geneva: WHO; 2009.

3. UNAIDS: UNAIDS Report On The Global Aids Epidemic, UNAIDS Global Report; 2010.

4. JM D, Ramakrishnan L: The role of the granuloma in expansion and dissemination of early tuberculous infection. Cell 2009, 136(1):37-49.

5. Maartens G, Wilkinson RJ: Tuberculosis. Lancet 2007, 370(9604):2030-2043.

6. Zaki HY, Leung KH, Yiu WC, Gasmelseed N, Elwali NE, Yip SP: Common polymorphisms in Tlr4 gene associated with susceptibility to pulmonary tuberculosis in the Sudanese. Int J Tuberc Lung Dis 2012, 16(7):934-940.

7. De Almeida AS, Fiske CT, Sterling TR, Kalams SA: Increased frequency of regulatory $T$ cells and $T$ lymphocyte activation in persons with previously treated extrapulmonary tuberculosis. Clin Vaccine Immunol 2012, 19(1):45-52.

8. Jones BE, Young SM, Antoniskis D, Davidson PT, Kramer F, Barnes PF Relationship of the manifestations of tuberculosis to $\mathrm{Cd} 4$ cell counts in patients with human immunodeficiency virus infection. Am Rev Respir Dis 1993, 148(5):1292-1297.

9. Lewinsohn DA, Gennaro ML, Scholvinck L, Lewinsohn DM: Tuberculosis immunology in children: diagnostic and therapeutic challenges and opportunities. Int J Tuberc Lung Dis 2004, 8(5):658-674.

10. Wirth T, Hildebrand F, Allix-Béguec C, Wölbeling F, Kubica T, Kremer K, Van Soolingen D, Rüsch-Gerdes S, Locht C, Brisse S, Meyer A, Supply P: Origin, spread and demography of the mycobacterium tuberculosis complex. PLoS Pathog 2008, 4(9):E1000160.

11. Lopez B, Agular D, Orozco H, Burger M, Espitia M, Ritacco V, Berrera L, Kremet K, Hemandez-Pando R, Huygen K, van Soolingen D: A marked difference in pathogenesis and immune response induced by different mycobacterium tuberculosis genotypes. Cl.Exp.Immunol 2003, 133(1):30-7.

12. Pareek M, Evans J, Innes J, Smith G, Hingley-Wilson S, Lougheed KE, Sridhar S, Dedicoat M, Hawkey P, Lalvani A: Ethnicity and mycobacterial lineage as 
determinants of tuberculosis disease phenotype. Thorax 2013, 68(3):221-229.

13. Nicol MP, Wilkinson RJ: The clinical consequences of strain diversity in mycobacterium tuberculosis. Trans R Soc Trop Med Hyg 2008, 102(10):955-965.

14. Asiimwe BB, Koivula T, Kallenius G, Huard RC, Ghebremichael S, Asiimwe J, Joloba ML: Mycobacterium tuberculosis Uganda genotype is the predominant cause of Tb in Kampala, Uganda. Int J Tuberc Lung Dis 2008, 12(4):386-391

15. Bazira J, Asiimwe BB, Joloba ML, Bwanga F, Matee Ml: Mycobacterium tuberculosis spoligotypes and drug susceptibility pattern of isolates from tuberculosis patients in South-Western Uganda. BMC Infect Dis 2011, 11:81.

16. Bazira J, Matte M, Asiimwe BB, Joloba LM: Genetic diversity of mycobacterium tuberculosis in Mbarara, South Western Uganda. Afr Health Sci 2010, 10(4):306-311.

17. Sharma SK, Mohan A: Extrapulmonary tuberculosis. Indian J Med Res 2004 120(4):316-353.

18. Yone EW, Kengne AP, Moifo B, Kuaban C: Prevalence and determinants of extrapulmonary involvement in patients with pulmonary tuberculosis in a Sub-Saharan African country: a cross-sectional study. Scand J Infect Dis 2013, 45(2):104-111.

19. Golden MP, Vikram HR: Extrapulmonary tuberculosis: an overview. Am Fam Physician 2005, 72(9):1761-1768.

20. Smith I: Mycobacterium tuberculosis pathogenesis and molecular determinants of virulence. Clin Microbiol Rev 2003, 16(3):463-496.

21. Fiske CT, Griffin MR, Erin H, Warkentin J, Lisa K, Arbogast PG, Sterling TR: Black race, sex and extrapulmonary tuberculosis risk: an observational study. BMC Infect Dis 2010, 10:16.

22. Fontanilla JM, Barnes A, Von Reyn CF: Current diagnosis and management of peripheral tuberculous lymphadenitis. Clin Infect Dis 2011 53(6):555-562

23. Patel MN, Beningfield S, Burch V: Abdominal and pericardial ultrasound in suspected extrapulmonary or disseminated tuberculosis. $S$ Afr Med $J$ 2011, 101(1):39-42.

24. Heller T, Goblirsch S, Bahlas S, Ahmed M, Giordani MT, Wallrauch C, Brunetti E: Diagnostic value of fash ultrasound and chest X-ray in Hiv-co-infected patients with abdominal tuberculosis [notes from the field]. Int J Tuberc Lung Dis 2013, 17(3):342-344

25. Meschede D, Keck C, Zander M, Cooper TG, Yeung CH, Nieschlag E: Influence of three different preparation techniques on the results of human sperm morphology analysis. Int J Androl 1993, 16(6):362-369.

26. Hsieh YC, Tsai KY, Wang CY, Hung CN, Tsai SS, Liu HJ: Diagnosis of avian tuberculosis in Swinhoe's pheasants using conventional and molecular-based techniques. Avian Dis 2009, 53(4):629-633.

27. Bezabih M, Mariam DW, Selassie SG: Fine needle aspiration cytology of suspected tuberculous lymphadenitis. Cytopathology 2002, 13(5):284-290.

28. Kent PT, Kubica GP: Public Health Mycobacteriology: A Guide for the Level III Laboratory. Atlanta, Ga: US Department Of Health And Human Services, Centres For Disease Control; 1985

29. Honore-Bouakline S, Vincensini JP, Giacuzzo V, Lagrange PH, Herrmann JL: Rapid diagnosis of extrapulmonary tuberculosis by Pcr: impact of sample preparation and Dna extraction. J Clin Microbiol 2003, 41(6):2323-2329.

30. Belisle JT, Sonnenberg MG: Isolation of genomic Dna from mycobacteria. Methods Mol Biol 1998, 101:31-44.

31. Maurya AK, Nag VL, Kant S, Kushwaha RAS, Kumar M, Mishra V, Rahman W, Dhole TN: Evaluation of an immunochromatographic test for discrimination between mycobacterium tuberculosis complex \& non tuberculous mycobacteria in clinical isolates from extra-pulmonary tuberculosis. Indian J Med Res 2012, 135(6):901-906.

32. Kamerbeek J, Schouls L, Kolk A, Van Agterveld M, Van Soolingen D, Kuijper S, Bunschoten A, Molhuizen H, Shaw R, Goyal M, Van Embden J: Simultaneous detection and strain differentiation of mycobacterium tuberculosis for diagnosis and epidemiology. J Clin Microbiol 1997, 35(4):907-914

33. Demay C, Liens B, Burguière T, Hill V, Couvin D, Millet J, Mokrousov I, Sola C, Zozio T, Rastogi N: Sitvitweb-a publicly available international multimarker database for studying mycobacterium tuberculosis genetic diversity and molecular epidemiology. Infect Genet Evol 2012, 12(4):755-766

34. Niemann S, Rusch-Gerdes S, Joloba ML, Whalen CC, Guwatudde D, Ellner JJ, Eisenach K, Fumokong N, Johnson JL, Aisu T, Mugerwa RD, Okwera A,
Schwander SK: Mycobacterium africanum subtype II is associated with Two distinct genotypes and is a major cause of human tuberculosis in Kampala, Uganda. J Clin Microbiol 2002, 40(9):3398-3405.

35. Lazarus AA, Thilagar B: Abdominal tuberculosis. Dis Mon 2007, 53(1):32-38

36. Kumar NP, Sridhar R, Banurekha W, Nair D, Jawahar MS, Nutman TB, Babu S: Expansion of pathogen-specific mono- and multifunctional Th1 and Th17 cells in multi-focal tuberculous lymphadenitis. PLoS One 2013, 8(2):E57123.

37. Marais BJ, Wright CA, Schaaf HS, Gie RP, Hesseling AC, Enarson DA, Beyers $\mathrm{N}$ : Tuberculous lymphadenitis as a cause of persistent cervical lymphadenopathy in children from a tuberculosis-endemic area. Pediatr Infect Dis J 2006, 25(2):142-146.

38. Gafirita J, Umubyeyi AN, Asiimwe BB: A first insight into the genotypic diversity of mycobacterium tuberculosis from Rwanda. BMC Clin Pathol 2012, 12:20.

39. Wampande EM, Mupere E, Debanne SM, Asiimwe BB, Nsereko M, Mayanja H, Eisenach K, Kaplan G, Boom HW, Sebastien G, Joloba ML: Long-term dominance of mycobacterium tuberculosis Uganda family in peri-urban Kampala-Uganda is not associated with cavitary disease. BMC Infect Dis 2013, 13(1):484.

40. Kan B, Berggren I, Ghebremichael S, Bennet R, Bruchfeld J, Chryssanthou E, Kallenius G, Petersson R, Petrini B, Romanus V, Sylvan S, Kalin M: Extensive transmission of an isoniazid-resistant strain of mycobacterium tuberculosis in Sweden. Int J Tuberc Lung Dis 2008, 12(2):199-204.

41. Sandegren L, Groenheit R, Koivula T, Ghebremichael S, Advani A, Castro E, Pennhag A, Hoffner S, Mazurek J, Pawlowski A, Kan B, Bruchfeld J, Melefors $\mathrm{O}$, Kallenius G: Genomic stability over 9 years of an isoniazid resistant mycobacterium tuberculosis outbreak strain in Sweden. PLoS One 2011, 6(1):E16647.

42. Lin PL, Myers A, Smith L, Bigbee C, Bigbee M, Fuhrman C, Grieser H, Chiosea I, Voitenek NN, Capuano SV, Klein E, Flynn JL: Tumor necrosis factor neutralization results in disseminated disease in acute and latent mycobacterium tuberculosis infection with normal granuloma structure in a cynomolgus macaque model. Arthritis Rheum 2010, 62(2):340-350.

43. Yang Z, Kong Y, Wilson F, Foxman B, Fowler AH, Marrs CF, Cave MD, Bates $\mathrm{JH}$ : Identification of risk factors for extrapulmonary tuberculosis. Clin Infect Dis 2004, 38(2):199-205.

44. Nambuya A, Sewankambo N, Mugerwa J, Goodgame R, Lucas S: Tuberculous lymphadenitis associated with human immunodeficiency virus (Hiv) in Uganda. J Clin Pathol 1988, 41(1):93-96.

45. Zenebe Y, Anagaw B, Tesfay W, Debebe T, Gelaw B: Smear positive extra pulmonary tuberculosis disease at university of Gondar hospital, northwest Ethiopia. BMC Res Notes 2013, 6:21.

46. Schubert PT, Cotton MF, Wright CA: Cytomorphological patterns of M. Bovis Bcg and M. Tuberculosis on fine needle aspiration biopsies: does Hiv make a difference? Diagn Cytopathol 2011, 39(4):264-269.

47. Pawlowski A, Jansson M, Skold M, Rottenberg ME, Kallenius G: Tuberculosis and HIV co-infection. PLOS Pathog 2012, 8(2):E1002464

48. Click ES, Moonan PK, Winston CA, Cowan LS, Oeltmann JE: Relationship between mycobacterium tuberculosis phylogenetic lineage and clinical site of tuberculosis. Clin Infect Dis 2012, 54(2):211-219.

49. Caws M, Thwaites G, Dunstan S, Hawn TR, Lan NT, Thuong NT, Stepniewska K, Huyen MN, Bang ND, Loc TH, Gagneux S, Soolingen DV, Kremer K, Van der Sande M, Small P, Anh PTH, Chinh NT, Quy HT, Duyen NTH, Tho LQ Hieu NT, Torok E, Hien TT, Dung NH, Nhu NTO, Duy PM, Chau PMD, Chau $\mathrm{NV}$ : The influence of host and bacterial genotype on the development of disseminated disease with mycobacterium tuberculosis. PLOS Pathog 2008, 4(3):E1000034.

50. Kong Y, Cave MD, Zhang L, Foxman B, Marrs CF, Bates JH, Yang ZH: Association between mycobacterium tuberculosis Beijing/w lineage strain infection and extrathoracic tuberculosis: insights from epidemiologic and clinical characterization of the three principal genetic groups of M tuberculosis clinical isolates. J Clin Microbiol 2007, 45(2):409-414.

51. Sun Y-J, Lim T, Ong A, Ho B, Seah G, Paton N: Tuberculosis associated with mycobacterium tuberculosis Beijing and non-Beijing genotypes: a clinical and immunological comparison. BMC Infect Dis 2006, 6(1):105.

52. Feng JY, Su WJ, Liu LY, Tsai CC, Chang SC: Radiological presentation of pulmonary tuberculosis infected by the W-Beijing mycobacterium tuberculosis strain. Int J Tuberc Lung Dis 2009, 13(11):1387-1392.

53. Borgdorff MW, Van Deutekom H, De Haas PE, Kremer K, Van Soolingen D: Mycobacterium tuberculosis, Beijing genotype strains not associated 
with radiological presentation of pulmonary tuberculosis.

Tuberculosis (Edinb) 2004, 84(5):337-340.

54. Thwaites G, Caws M, Chau TT, D'sa A, Lan NT, Huyen MN, Gagneux S, Anh PT, Tho DQ, Torok E, Nhu NTQ, Duyen NTH, Duy PM, Richenberg J, Hien TT, Simmons C: Relationship between mycobacterium tuberculosis genotype and the clinical phenotype of pulmonary and meningeal tuberculosis. J Clin Microbiol 2008, 46(4):1363-1368.

55. Viegas SO, Machado A, Groenheit R, Ghebremichael S, Pennhag A, Gudo PS, Cuna Z, Langa E, Miotto P, Cirillo DM, Rostagi N, Warren RM, Van Helden PD, Kiovula T, Kallenius G: Mycobacterium tuberculosis Beijing genotype is associated with HIV infection in Mozambique. PLoS One 2013, 8(8):E71999.

56. Carmona J, Cruz A, Moreira-Teixeira L, Sousa C, Sousa J, Osorio NS, Saraiva AL, Svenson S, Kallenius G, Pedrosa J, Rodrigues F, Castro AG, Saraiva M: Mycobacteria tuberculosis strains are differentially recognized by tlrs with an impact on the immune response. PLoS One 2013, 8(6):E67277.

57. Firdessa R, Berg S, Hailu E, Schelling E, Gumi B, Erenso G, Gadisa E, Kiros T, Habtamu M, Hussein J, Zinsstag J, Robertson BD, Ameni G, Lohan AJ, Loftus B, Comas I, Gagneaux S, Tsochopp R, Yamuah L, Hewinson G, Gordon SV, Young DB, Aseffa A: Mycobacterial lineages causing pulmonary and extrapulmonary tuberculosis, Ethiopia. Emerg Infect Dis 2013, 19(3):460-463

58. Nicol MP, Sola C, February B, Rastogi N, Steyn L, Wilkinson RJ: Distribution of strain families of mycobacterium tuberculosis causing pulmonary and extrapulmonary disease in hospitalized children in Cape Town, South Africa. J Clin Microbiol 2005, 43(11):5779-5781.

59. Portevin D, Gagneux S, Comas I, Young D: Human macrophage responses to clinical isolates from the mycobacterium tuberculosis complex discriminate between ancient and modern lineages. PLoS Pathog 2011, 7(3):E1001307.

60. Nahid P, Bliven EE, Kim EY, Mac Kenzie WR, Stout JE, Diem L, Johnson JL, Gagneux S, Hopewell PC, Kato-Maeda M: Influence of M. Tuberculosis lineage variability within a clinical trial for pulmonary tuberculosis. PLoS One 2010, 5(5):E10753.

doi:10.1186/1472-6890-14-14

Cite this article as: Wamala et al: Clinico-pathological features of tuberculosis due to Mycobacterium tuberculosis Uganda genotype in patients with tuberculous lymphadenitis: a cross sectional study. BMC Clinical Pathology 2014 14:14.

\section{Submit your next manuscript to BioMed Central and take full advantage of:}

- Convenient online submission

- Thorough peer review

- No space constraints or color figure charges

- Immediate publication on acceptance

- Inclusion in PubMed, CAS, Scopus and Google Scholar

- Research which is freely available for redistribution

Submit your manuscript at www.biomedcentral.com/submit
C Biomed Central 